del maestro- como punto de partida y de retorno para la exploración de los principales aspectos de la teoría y de la praxis de James como historiador epistemológico y como filosofo, ya que, al igual que sugiere Lambert Strether, quizá el personaje jamesiano que más se acerca a la propia personalidad de su autor, "we want none of our problems poor" ( $\mathrm{Am}$ bassadors 273).

Otras obras citadas

Cannon, Kelly. Henry James and Masculinity. The Man at the Margin. London: MacmiIlan, 1994.

JAMES, Henry. Autobiography: A Small Boy and Others, Notes of a Son and Brother, The Middle Years. Ed. Federick W. Dupee. Princeton, New Jersey: Princeton U P, 1983. Las citas, tomadas de esta edición, aparecen directamente con la inicial $(A)$.

-, Hawthorne. (Essays on Literature, American Writers, Literary Criticism, vol. 1. Library of America). New York: Literary Classics of the U.S., Inc. 1984.

-, The Ambassadors. New York Edition. Vol. XXI-II. New York: Charles Scribener's Sons, 1907-17.

RigHTER, William. American Memory in Henry James. Void and Value. Hampside (England) / Burlington (U.S.A.): Ashgate Publishing Limited, 2004.

\section{María Antonia Álvarez}

Romera Casttllo, José (ed.), Teatro y memoria en la segunda mitad del siglo $X X$. Madrid: Visor Libros / UNED, 2003, 582 páginas.

En el Centro de Investigación de Semiótica Literaria, Teatral y Nuevas Tecnologías, bajo la dirección del profesor José Romera Castillo, se llevan a cabo una serie de actividades (que pueden verse en la página web http://www.uned.es/centroinvestigacion-SELITEN@T), relacionadas con diferentes aspectos de la investigación más puntera en España, tanto en la metodología como en los temas abordados.

En este volumen se aúnan dos de las líneas de investigación más destacadas que se cultivan en su seno. De un lado, la referida a lo autobiográfico; y, de otro, la relacionada con lo teatral.

En efecto, este Centro de investigación constituye una de las referencias obligadas para el estudio de la escritura autobiográfica (desde 1975), como muy bien ha pormenorizado José Romera Castillo, en su trabajo, «Investigaciones sobre escritura autobiográfica en el SELITEN@T de la Universidad Nacional de Educación a Distancia», en Vicente Granados Palomares (ed.), Actas XXI Simposio Internacional de Literatura y Sociedad (Madrid: UNED, 2003, págs. 205-220). Varios han sido los Seminarios Internacionales, celebrados en la UNED, que han centrado su atención tanto sobre lo biográfico: José Romera Castillo y Francisco Gutiérrez Carbajo (eds.), Biografias literarias (19751997) (Madrid: Visor Libros, 1998), como en lo autobiográfico: José Romera Castillo et alii (eds.), Escritura autobiográfica (Madrid: Visor Libros, 1993) y Poesía histórica y (auto)biográfica (1975-1999) (Madrid: Visor Libros, 2000).

Asimismo, el teatro (textos y representaciones) ha merecido una atención diligente, como ponen de manifiesto los diversos Seminarios dedicados a su estudio: José Romera Castillo (ed.), Teatro histórico (1975-1998): textos y representaciones (Madrid: Visor Libros, 1999), Del teatro al cine y la televisión en la segunda mitad del siglo XX (Madrid: Visor Libros, 2002), Teatro, prensa y nuevas tecnologias (19902003) (Madrid: Visor Libros, 2004), Dra- 
maturgias femeninas en la segunda mitad del siglo XX: espacio y tiempo (Madrid: Visor Libros, 2005) y Tendencias escénicas al inicio del siglo XXI (Madrid: Visor Libros, 2006, en prensa).

Teatro y memoria en la segunda mitad del siglo $\mathrm{XX}$, recoge las ponencias y comunicaciones presentadas en el XII Seminario Internacional del SELITEN@T, celebrado en la UNED del 26 al 28 de junio de 2002 , el primer foro monográfico de discusión y estudio que se ha dedicado al tema en España. El libro consta de tres partes.

Tras la documentada «Presentación» del director, José Romera Castillo, en la que se pormenorizan los frutos obtenidos en estas dos ramas de las investigaciones que se llevan a cabo en el Centro, aparecen las catorce «Sesiones plenarias», impartidas tanto por dramaturgos (Ignacio Amestoy y Paloma Pedrero, págs. 23-39 y 4145, exponen su experiencia en el trasvase de los hechos vividos a su escritura dramática) como por destacados especialistas de diferentes universidades que se centran en el estudio de diversas manifestaciones sobre nuestro tema. A la contribución globalizadora de Virtudes Serrano (Universidad de Murcia), que trata de lo autobiográfico en la dramaturgia femenina española actual (págs. 47-62), le siguen otras que estudian a los autores - presentados en el volumen por orden alfabético, para evitar suspicacias-y obras (teatrales y memorialísticas) como las de Margarita Piñero (RESAD), sobre ¡Viva el duque, nuestro dueño! de José Luis Alonso de Santos (págs. 63-76); Mariano de Paco (Universidad Murcia), sobre la huellas vivenciales en el teatro de Buero y Alfonso Sastre (págs. 77-94); Francisco Gutiérrez Carbajo (UNED), sobre Alfonso Vallejo (págs. 95-106); Joseph Lluís Sirera (Universitat de València), sobre el teatro catalán contemporáneo (págs. 107-
117); Samuel Amell (The Ohio State University), sobre Fernán-Gómez (págs. 119129); Juan Antonio Hormigón (Director teatral y RESAD), sobre Marsillach (págs. 131-140) y Jesús Rubio Jiménez (Universidad de Zaragoza), sobre Francisco Nieva (págs. 141-157). Otros trabajos se detienen en el análisis de varios autores y obras como las de Anna Caballé (Universidad de Barcelona), que se centra en tres vidas y tres autobiografías: las de A. Marsillach, A. Boadella y F. Nieva págs. 159-170); José Antonio Pérez Bowie (Universidad de Salamanca, que reflexiona y da noticia de adaptaciones cinematográficas de textos teatrales en escritos autobiográficos de Luis Escobar, Fernán-Gómez, Bardem y Sáenz de Heredia (págs. 171-186); José Antonio Ríos Carratalá (Universidad de Alicante), que continúa con sus estudios sobre cómicos ante el espejo (págs. 187-199) y Alberto Romero Ferrer (Universidad de Cádiz), que se detiene en el examen de algunas (auto)biografías de actores y actrices entre el documento y la hagiografía civil (págs. 201-217).

En la segunda parte, el grupo de investigación del SELITEN@T, bajo la coordinación del prof. Romera Castillo, realiza un exhaustivo estado de cuestión de los textos autobiográficos - en sus diversas manifestaciones- producidos por diversos integrantes del espectáculo teatral, desde 1950 a 2002: José Romera Castillo (UNED) traza los perfiles autobiográficos de la denominada Otra generación del 27(la del humor), con referencias a Miguel Mihura, Edgar Neville, Jardiel Poncela, Antonio Lara (Tono), a los que fueron a Hollywood, etc. (págs. 221-243); Olga Elwes Aguilar, se centra en los textos de los dramaturgos posteriores (págs. 245-255); Irene Aragón González, en los de los directores de escena (págs. 257-283); Dolores Romero López, en los de las actrices 
(págs. 285-312); Rosa Ana Escalonilla y Francisco Ernesto Puertas Moya, en los de los actores (págs. 313-332 y 333-342, respectivamente). Todo un conjunto de textos autobiográficos y de análisis de los mismos que serán de gran utilidad para conocer mejor la trayectoria de nuestro teatro.

En la tercera parte se publican las veintidós «Comunicaciones», que fueron expuestas en el Seminario, tras una estricta selección. Aunque en el volumen se presentan por el orden alfabético de sus autores, prefiero agruparlas en esta reseña para una mayor comodidad de mis lectores.

Sobre dramaturgos españoles versan los trabajos de Eusebio Cedena Gallardo (SELITEN@T), sobre María Teresa León (págs. 413-420); Araceli Maira Benítez (SELITEN@T), sobre María Martínez Sierra (págs. 465-473); José V. Peiró Barco (UNED, Alzira), sobre José Ricardo Morales (págs. 509-517); M. ${ }^{a}$. Isabel Aboal Sanjurjo (Universidad de Murcia), sobre Alfonso Sastre (págs. 345-354); Catalina Buezo Canalejo (Universidad Europea de Madrid), sobre Jaime de Armiñán (págs. 401-412); Miguel Héctor Fernández-Carrión (UNED) y Carole Nabet Egger (Université de Provence), sobre Miguel Romero Esteo (págs. 437-445 y 489-497, respectivamente); Ana Suárez Miramón (UNED), sobre Marsillach y los clásicos (págs. 541-559); Alicia Molero de la Iglesia (SELITEN@T), sobre Albert Boadella (págs. 475-487); Antonio F. Pedrós-Gascón (The Ohio State University), sobre Suso de Toro (págs. 499-507); Agnès Surbezy (Université de Toulouse-Le Mirail), sobre Borja Ortiz de Gondra (págs. 561571); además del trabajo más global de Emilia Cortés Ibáñez (UNED, Albacete), sobre algunas claves teatrales en los escritos memorialísticos de L. Escobar, F. FernánGómez y A. Marsillach (págs. 421-436).

El teatro catalán lo estudia Trinidad Barbero Reviejo (I.E.S Vinyes Velles,
Montornés, Barcelona), sobre el epistolario de Francesc Curet (págs. 373-382); así como el vasco lo hace Loreta de Stasio (Universidad del País Vasco) al tratar de las memorias contadas del director y actor Pedro Barea (págs. 527-539).

Varios trabajos versan sobre la dramaturgia hispanoamericana: Robert Baah (Seatle Pacific University) estudia escritos de la mexicana Elena Garro (págs. 365-372); María Florencia Bendersky (Dramaturga) analiza la experiencia de la memoria en el argentino Teatroxlaidentidad (págs. 383389) y Miguel Herráez (Universidad de Valencia) se detiene en el autobiografismo de Julio Cortázar en su discurso teatral (págs. 457-463).

Sobre el teatro en otras lenguas versan los trabajos de Marina Sanfilippo (UNED), que estudia narraciones autobiográficas de algunos dramaturgos italianos de los años noventa (págs. 519-526); Marília Regina Brito (Universidade Fernando Pessoa, Porto, Portugal) analiza O Irmâo, de David Mourao-Ferreira (págs. 391-400) e Isabel Vaz Ponde de Leâo (Universidade Fernando Pessoa, Porto) examina el diario intimo de José Régio (págs. 573-580); Verónica D. Fernández Peebles (Universidad de La Coruña) trata sobre Peter Brook (págs. 447-456 y M. ${ }^{a}$ Antonia Álvarez Calleja (UNED) analiza las memorias de la norteamericana Sandra Cisneros (págs. 355-363).

Con esta nómina, tan completa, de estudios de dramaturgos y de sus obras autobiográficas el investigador dispone de un muy completo panorama y de unos análisis que servirán tanto para conocer mejor la producción de textos autobiográficos en el mundo del espectáculo teatral como para la reconstrucción de la vida escénica en la segunda mitad del siglo XX.

Sandra Álvarez de Toledo 